\section{A diversidade do HIV-1: uma ferramenta para o estudo da pandemia}

\author{
HIV-1 diversity: a tool for studying the pandemic
}

\author{
1 Instituto de Biologia, \\ Universidade Federal \\ do Rio de Janeiro, \\ Rio de Janeiro, Brasil. \\ 2 Escola Nacional de Saúde \\ Pública Sergio Arouca, \\ Fundação Oswaldo Cruz, \\ Rio de Janeiro, Brasil. \\ 3 Instituto de Medicina \\ Social, Universidade do \\ Estado do Rio de Janeiro, \\ Rio de Janeiro, Brasil. \\ Correspondência \\ M. E. Pinto \\ Laboratório de \\ Biodiversidade Molecular, \\ Departamento de Genética, \\ Instituto de Biologia, \\ Universidade Federal \\ do Rio de Janeiro. \\ Av. Pau Brasil 211, Bloco A, \\ Rio de Janeiro, $R J$ \\ 21941-590, Brasil. \\ monica@procc.fiocruz.br
}

\begin{abstract}
$H I V-1$ is remarkable for the diversity of strains comprising the HIVIAIDS pandemic. In the last decade, classification of viral variants as groups, subtypes, and circulating recombinant forms (CRF) and the observation of specific mutational patterns have become powerful tools for studying viral molecular dynamics. Monitoring the worldwide distribution of HIV-1 diversity has been used in both epidemiological surveillance programs and in reconstructing the history of regional epidemics. Specific patterns of virus spatial distribution also suggest differences in pathogenicity and transmissibility among the various subtypes. Molecular analyses of viral sequences allow estimating the rate of divergence among variants and the dynamic forces shaping the phylogenetic trees.
\end{abstract}

HIV-1; Acquired Immunodeficiency Syndrome; Molecular Epidemiology
Mônica Edelenyi Pinto ${ }^{1}$

Claudio José Struchiner ${ }^{2,3}$

\section{Introdução}

A epidemiologia molecular tem se mostrado uma ferramenta valiosa para o estudo das epidemias de doenças infecciosas, uma vez que permite que as informações moleculares acumuladas nos genomas dos microorganismos sejam utilizadas para se reconstruir e se prever o seu curso 1 . Um exemplo significativo é a história da interação do vírus da imunodeficiência humana tipo 1 (HIV-1) com as populações humanas ao longo das últimas décadas.

O HIV-1 se caracteriza por uma enorme variabilidade genética e antigênica. Na região que codifica as glicoproteínas do envelope (gene $e n v$ ), por exemplo, estima-se que a magnitude da diversidade possa ser superior a $10 \%$ em um único paciente e chegue até $50 \%$ entre cepas de diferentes grupos 2 . Ironicamente, esta variabilidade, uma das principais razões da dificuldade para o desenvolvimento de vacinas e para o tratamento com drogas anti-retrovirais, permitiu a reconstrução de diversos aspectos da história evolutiva do vírus ${ }^{3}$. Este artigo revisa a possibilidade da epidemiologia molecular ser utilizada na reconstrução de aspectos relevantes da epidemia de HIV/AIDS, levando em conta suas dimensões temporal, espacial e temporo-espacial: a introdução do HIV na espécie humana, sua dispersão na epidemia e possíveis diferenças relacionadas à transmissibilidade $\mathrm{e}$ à patogenia das diferentes cepas de HIV-1. De- 
vido à amplitude do tema, entretanto, questões importantes para o enfrentamento da epidemia, como o desafio imposto pela diversidade do vírus sobre o desenvolvimento de drogas anti-retrovirais e de vacinas, serão excluídas do texto.

A bibliografia citada no texto foi obtida da base bibliográfica PubMed e a sua busca foi orientada por combinações das palavras-chave: HIV-1, diversity, variability, subtypes molecular epidemiology, epidemiology, review, pathogeny, transmissibility, phenotype and origin and evolution.

\section{A diversidade do HIV-1}

Na tentativa de organizar a grande diversidade observada entre as cepas de HIV-1 que circulam na epidemia, até 1992 as variantes do vírus eram identificadas como "americanas" ou "africanas", com base em seu local de origem. Com a descoberta de novos espécimes, esta separação tornou-se inadequada e foi a princípio proposta uma classificação em subtipos com base na análise dos genes env ou gag. Atualmente, a classificação adotada se baseia na análise do genoma completo de amostras de HIV-1 colhidas em diferentes regiões geográficas: grupo $\mathrm{M}$ (major), composto por nove subtipos nomeados A-D, F-H, J e K (as variantes dos subtipos A e F são ainda segregadas como sub subtipos A1 ou A2 e F1 ou F2, respectivamente), e grupos $\mathrm{O}$ (out-group) 4 e $\mathrm{N}$ (new) 5 . Além destes, 16 formas recombinantes (CRF) circulam na epidemia, sendo as mais comuns as CRF02_AG e CRF01_AE 6 .

A organização das variantes do HIV-1 em grupos, subtipos, sub subtipos e CRF foi seguida de uma explosão de trabalhos na literatura descrevendo a diversidade do vírus nas epidemias regionais. O somatório destes esforços resultou no mapeamento, mesmo que incompleto, da distribuição mundial das variantes do HIV-1 e na observação de padrões de distribuição possivelmente relevantes para a compreensão da dinâmica da epidemia. Um exemplo é o questionamento sobre a existência de diferenças na transmissibilidade e na patogenia dos subtipos do grupo M.

\section{A origem da diversidade nos hospedeiros infectados}

O HIV-1 é um retrovírus e o seu conteúdo genético está disposto em duas fitas simples de RNA. A base molecular da extrema variabilidade dos retrovírus é o fato de sua enzima transcriptase reversa (TR) não possuir a proprieda- de de correção durante o processo de replicação viral, propriedade esta comum à DNA-polimerase de outros organismos. Esta ausência de correção resulta em uma taxa de erro na incorporação de nucleotídeos de aproximadamente $10^{-3}$ a $10^{-5}$ por sítio, por ciclo de replicação (a taxa de erro das DNA polimerases está em torno de 10-8 substituições/sítio/ciclo de replicação). No caso do HIV-1, o seu genoma, com aproximadamente 10 mil pares de bases, a cada ciclo de replicação adquire em média uma substituição de nucleotídeos 7. Considerando-se que, a cada dia, são produzidas em média 1010 novas partículas virais 8, é possível imaginar-se a imensa diversidade potencialmente gerada durante o longo curso da infecção.

Além dos erros na incorporação de nucleotídeos, um processo conhecido como recombinação homóloga também contribui para a variabilidade genética do HIV-1. Durante a transcrição reversa, a enzima TR pode "pular" de uma fita de RNA para outra, produzindo uma fita de DNA viral que contém segmentos dos dois RNA iniciais 9. Entretanto, para que a recombinação contribua substancialmente para a geração de diversidade, é necessário que as duas fitas de RNA encontradas em uma partícula viral sejam distintas uma da outra, ou seja, é necessário que, anteriormente, tenha ocorrido a produção de genomas virais "heterozigotos". Por sua vez, a formação de genomas "heterozigotos" depende de que, em algum momento, uma única célula do hospedeiro tenha sido infectada simultaneamente por duas variantes do vírus 9,10.

Uma conseqüência da complexidade de populações virais como as encontradas nos hospedeiros do HIV-1 é que estas populações são capazes de responder rápida e eficientemente às perturbações do ambiente onde se replicam, porque oferecem um grande espectro de mutantes sobre os quais a seleção natural pode atuar. Quando existem alterações no ambiente, por exemplo, pela administração de drogas antivirais, a presença de um ou mais mutantes mais aptos a replicar neste novo meio faz com que a população derivada desses mutantes ganhe aptidão (fitness) e aumente suas chances de sobreviver. No caso do HIV-1, a pressão seletiva exercida constantemente pelo sistema imune resulta na adaptação do vírus a novas células-alvo e na manutenção de uma infecção persistente 7 .

Durante a transmissão do HIV-1 a um novo hospedeiro susceptível, entretanto, observa-se um significativo estreitamento da diversidade da população de vírus (bottleneck), de modo que a progênie viral produzida no início da in- 
fecção resulta da expansão de uma ou poucas partículas virais. Diversos fatores impõem esse estreitamento, como: a resposta imune inata; a densidade de células-alvo no local da infecção; o número de partículas virais transmitidas; e a estrutura da população viral do hospedeiro transmissor 11 .

Além do estreitamento da diversidade, durante a transmissão do HIV-1 também ocorre um processo de seleção natural, de modo que os vírus encontrados nos estágios iniciais da infecção possuem características distintas daqueles observados nos estágios mais tardios da imunodeficiência. De um modo geral, os isolados virais de indivíduos nos estágios iniciais apresentam baixas taxas de replicação, não possuem capacidade de induzir a formação de sincícios em células MT-02, replicam com maior eficiência em macrófagos e utilizam preferencialmente o co-receptor CCR5 para infectar a célula. Por outro lado, em estágios avançados, uma grande parte das cepas virais apresenta altas taxas de replicação, replica-se com maior eficiência em células $\mathrm{T}$ e utiliza a molécula CXCR4 como co-receptor. Além disto, em aproximadamente $50 \%$ dos indivíduos, os vírus adquirem a capacidade de induzir sincícios em culturas de células. Entretanto, apesar das variantes que utilizam o co-receptor CXCR4 dominarem as populações virais nas fases mais avançadas da imunodeficiência, as variantes CCR5 são tipicamente transmitidas para os hospedeiros durante o processo de infecção 11,12.

\section{A origem da diversidade na população humana}

A análise filogenética das variantes dos três grupos de HIV-1 e de seqüências do HIV-2 (o outro vírus humano relacionado à AIDS) foi uma peça importante na montagem de um dos quebra-cabeças mais instigantes da epidemia de HIV/AIDS: a história da introdução do vírus na espécie humana. Neste sentido, apesar de uma conexão entre os lentivírus humanos (HIV1 e -2) e retrovírus de primatas (Simian Immunodeficiency Virus, SIV) ter sido sugerida desde o início da epidemia, a reconstrução das relações filogenéticas entre as principais variantes do HIV e os SIV somente foi conseguida na medida em que mais e mais vírus foram isolados de diferentes espécies de símios.

Em contrapartida, a inferência das relações evolutivas entre os HIVs e os SIVs identificados possibilitou a elucidação da origem zoonótica da epidemia da AIDS, bem como das circunstâncias e dos fatores que contribuíram para o seu início. Para substanciar a origem da epide- mia humana, cinco linhas de evidências têm sido utilizadas: (1) as similaridades na organização do genoma dos HIVs e SIVs; (2) as suas relações filogenéticas; (3) a prevalência dos SIVs nos seus hospedeiros naturais; (4) a coincidência geográfica entre os dois vírus; e (5) a existência de vias plausíveis de transmissão entre espécies 13.

A reconstrução das relações evolutivas entre os dois tipos de HIV e os SIV permitiu não somente a identificação das espécies de símios que forneceram os ancestrais diretos dos vírus humanos. Uma inferência também importante foi a de que a epidemia da AIDS, na realidade, resulta de pelo menos sete eventos de transmissão zoonótica de vírus de primatas, das quais quatro deram origem aos subtipos de HIV-2 enquanto as outras três fundaram, cada uma, os grupos M, N e O do HIV-1 13. Entretanto, apesar da provável ocorrência das sete introduções na espécie humana, a pandemia está associada aos subtipos e formas recombinantes do grupo $\mathrm{M}$.

A origem zoonótica do HIV-2 foi a primeira a ser elucidada, com o isolamento do $\operatorname{SIV}_{\mathrm{sm}}$ de primatas da espécie Cercocebus atys ${ }^{14}$. Em relação ao HIV-1, por algum tempo o $\mathrm{SIV}_{\mathrm{agm}}$, isolado de macacos verdes da África (Chlorocebus aethiops) 15, foi considerado o seu provável ancestral direto 16. Entretanto, a relação entre os dois vírus permanecia controversa. Um ponto de consenso entre os autores era o local de origem da epidemia da AIDS: o oeste da África Equatorial (alguns se referem à região como África Central). Duas evidências suportavam esta teoria. Em primeiro lugar, a África Equatorial é a região onde a maior diversidade de variantes do vírus é encontrada: além de representantes dos grupos $\mathrm{N}$ e $\mathrm{O}$, todos os subtipos do grupos $\mathrm{M}$ e diversas formas recombinantes co-circulam nos Camarões, na Guiné Equatorial, no Gabão e na República Democrática do Congo 17. Em segundo lugar, a amostra soropositiva para o HIV-1 mais antiga foi colhida em 1959, no antigo Zaire (atual República Democrática do Congo) 18.

Somente na década de 90, a identificação de retrovírus de chimpanzés (Pan troglodytes troglodytes), $\mathrm{SIV}_{\mathrm{cpz}}$, resolveu a questão sobre a origem zoonótica do HIV-1 19,20 pois: (1) os dois vírus compartilham a mesma estrutura genômica; (2) vírus de chimpanzés e variantes do HIV-1 se agrupam próximos nas árvores filogenéticas; (3) existem evidências indiretas de que a infecção de chimpanzés pelo SIV não é um evento incomum; (4) chimpanzés e representantes de todos os grupos de HIV-1 compartilham a mesma região geográfica (o oeste da 
África Equatorial); e (5) a carne de chimpanzés é utilizada como alimento na região, o que evidencia a oportunidade do SIV ter infectado a espécie humana 13.

\section{Estudos de subtipagem}

A organização das variantes do HIV-1 em subtipos é amplamente utilizada nos estudos de epidemiologia molecular. Para evitar erros relativos a genomas recombinantes, o método de escolha para a classificação do HIV-1 em subtipos é a análise filogenética do genoma completo do vírus. Esta abordagem, contudo, por ser demorada e ter um alto custo, não pode ser aplicada em larga escala e deve ser integrada a inquéritos de epidemiologia molecular que incluam técnicas mais acessíveis 21 . Uma alternativa utilizada com freqüência é o seqüenciamento e a análise filogenética de pequenos fragmentos do genoma do vírus. Entretanto, mesmo esta abordagem pode ser inacessível para grupos de pesquisa de países em desenvolvimento ou, simplesmente, inaplicáveis a estudos envolvendo um grande número de amostras. Com isto, técnicas alternativas foram desenvolvidas para a caracterização da diversidade genética das variantes do HIV-1, das quais a mais utilizada é o ensaio de mobilidade de heteroduplexes (Heteroduplex Mobility Assay, HMA). Uma outra possibilidade é a análise do polimorfismo de restrição dos genes da protease e do envelope. A seguir, os princípios e aplicações das duas técnicas serão expostos resumidamente.

\section{Ensaio de mobilidade de heteroiduplexes}

O HMA para a subtipagem de variantes do HIV-1 se baseia na observação de que fragmentos de DNA amplificados por PCR, quando anelados aleatoriamente, formam híbridos (heteroduplexes) que migram com menor velocidade à eletroforese 22,23 . Na execução da técnica, produtos de amplificação por PCR de amostras desconhecidas e de cepas-referência (selecionadas como representativas da diversidade do HIV-1 na região geográfica em questão) são misturados e anelados; quanto maior a similaridade entre o fragmento da cepa desconhecida e a cepa-referência, maior é a velocidade de migração à eletroforese em gel. Esta técnica é freqüentemente empregada para a caracterização molecular do gene $e n v$, apesar de também poder ser utilizada para a subtipagem do gene gag 24 .

A técnica de HMA pode ser usada para a análise dos vírus presentes em diversos espéci- mes clínicos: sangue total adsorvido em papel, lisado de células mononucleares do sangue periférico, plasma ou soro e fluidos genitais. $\mathrm{Ou}$ tra vantagem é que a classificação de amostras de HIV-1 em subtipos por HMA possui quase $100 \%$ de correspondência com o seqüenciamento e a análise filogenética 22 . Por estas razões e devido ao seu menor custo e à sua rapidez de execução, quando comparado ao seqüenciamento, o HMA é amplamente utilizado para a subtipagem do HIV-1 nos países em desenvolvimento. Por outro lado, uma importante limitação da técnica é que, uma vez que depende da amplificação de uma região genômica por PCR, os primers utilizados para a amplificação podem não ser capazes de reconhecer as seqüências complementares no caso de vírus especialmente divergentes 21 .

\section{Análise do polimorfismo de restrição}

Uma outra abordagem utilizada para a caracterização de subtipos é a análise do polimorfismo de restrição de determinadas regiões do genoma do HIV-1. De uma maneira geral, a técnica é direcionada ao polimorfismo do gene da protease $25,26,27$, mas também pode ser aplicada à região do envelope para a caracterização da variante $\mathrm{BBr}$, que apresenta na alça $\mathrm{V} 3$ do envelope a seqüência de aminoácidos GWGR 28. A identificação de vírus $\mathrm{BBr}$ pelo polimorfismo de restrição é particularmente útil no Brasil, onde um grande número de casos de infecção é atribuído a esta variante do subtipo B 29,30.

\section{Limitações dos estudos de subtipagem}

De um modo geral, os estudos de subtipagem possuem limitações relacionadas aos métodos empregados para a caracterização molecular do vírus e aos desenhos dos estudos. Em primeiro lugar, em sua quase totalidade, os estudos de subtipagem utilizam amostras obtidas por conveniência, não considerando as distribuições dos casos segundo grupo sob risco, idade e tempo de infecção. Em conseqüência, seus resultados podem ser viciados e não representativos da população infectada. Além disto, o custo das técnicas empregadas pode não ser acessível aos países em desenvolvimento. Assim, considerando-se a epidemia mundial, os dados sobre a distribuição dos subtipos não são homogêneos: enquanto existem relativamente poucas seqüências disponíveis de variantes que circulam em regiões com grande número de indivíduos infectados (por exemplo, Moçambique, Angola e República Dominicana), há dados na literatura sobre os vírus que 
compõem as epidemias da Suécia, da Dinamarca e da Finlândia, países com baixa prevalência de infecção. Isto mostra que o conhecimento que se tem da diversidade do HIV-1 é incompleto, abrindo caminho para a existência de variantes distintas dos vírus descritos até o momento.

Em segundo lugar, as técnicas comumente empregadas para a caracterização das variantes do HIV-1 se baseiam na análise de pequenos fragmentos do seu genoma. Nestes casos, devido ao grande número de cepas recombinantes que circulam na epidemia, é recomendado que os resultados indiquem qual segmento foi utilizado na análise 31 . Uma abordagem freqüentemente empregada para a identificação de vírus recombinantes é a análise de mais de uma região do genoma do HIV-1 32,33,34,35.

\section{Subtipos diferem quanto à transmissibilidade e patogenia?}

A distribuição das variantes do HIV-1 na população humana é extremamente heterogênea. Os estudos seccionais conduzidos em diferentes partes do mundo mostram que as freqüências dos subtipos dentro de uma única população podem variar tanto em função do tempo quanto dos grupos sob risco estudados. Apesar da circulação das variantes ser uma decorrência natural do intenso fluxo humano intra e intercontinental, é possível que a sua distribuição geográfica seja também influenciada por características dos vírus, como transmissibilidade 36 e patogenia 37 .

Entretanto, a associação entre subtipos e risco de transmissão do HIV-1 e progressão para AIDS representa um desafio, pois os dois desfechos dependem de múltiplos fatores, relacionados aos hospedeiros e às condições do meio em que vivem $38,39,40$. Nos dois casos, a melhor abordagem seria o estabelecimento de estudos prospectivos em regiões onde mais de um subtipo circulam, como a África. Contudo, neste caso, às dificuldades inerentes a estudos de seguimento (longos períodos de acompanhamento, custo elevado, por exemplo) se somam outras específicas da epidemia, como número relativamente pequeno de soro-convertores recentes 21 . Quanto às análises de sobrevida, uma dificuldade adicional é a longa duração da fase assintomática da infecção antes do desenvolvimento dos sintomas definidores de AIDS.

\section{Diferenças na transmissibilidade}

Há alguns anos, foi sugerido que os vírus dos subtipos B, C e o recombinante CRF01_AE diferiam quanto à transmissibilidade 21,41 . Isto porque, principalmente na Tailândia, os vírus do subtipo B estão especialmente associados a infecções por uso de drogas injetáveis, enquanto os vírus CRF01_AE são mais freqüentemente encontrados nos indivíduos infectados por contato sexual. Uma vez que uma diferença semelhante foi encontrada entre os subtipos B e C na África do Sul 42 , alguns trabalhos in vitro foram conduzidos no sentido de estudar a eficiência destes vírus em infectar diferentes células em cultura.

Nesse sentido, foi inicialmente mostrado que os vírus C e CRF01_AE eram mais eficientes em infectar células de Langerhans do que os vírus do subtipo B. Uma vez que estas células são encontradas em grandes quantidades na vagina, no cérvix e na glande, e estão, via de regra, ausentes no reto, os autores sugeriram que o tropismo celular observado in vitro fosse um indicador da eficiência de transmissão por contato heterossexual 36. Contudo, trabalhos subseqüentes não confirmaram estes resultados 43,44,45. Assim, se existem diferenças na transmissibilidade de variantes do HIV-1, estas diferenças não foram ainda demonstradas. Possíveis abordagens para se testar a hipótese poderiam incluir estudos de casais discordantes para a infecção pelo HIV-1, a determinação da carga viral nos fluidos genitais e no plasma, e a utilização de estudos para se investigar a transmissibilidade no contexto da transmissão vertical (apesar desta informação não poder ser extrapolada para a avaliação da transmissão sexual) 21 .

\section{Diferenças na progressão para AIDS}

Os primeiros indícios de que subtipos do grupo $\mathrm{M}$ estariam relacionados a diferenças na patogenia vieram da observação de que cepas do subtipo D possuem maior número de aminoácidos com carga positiva (lisina e arginina) na região da alça $\mathrm{V} 3$ do gene $e n v 46$ do que vírus dos demais subtipos. Uma vez que a carga positiva na região está associada à progressão da imunodeficiência 12 , foi sugerido que variantes do subtipo D fossem mais patogênicas do que as demais. De fato, vírus do subtipo D extremamente citopáticos foram descritos in vitro 37 .

O primeiro estudo prospectivo para avaliar a progressão para AIDS em indivíduos infectados por subtipos não-B com tempo de infecção conhecido foi conduzido por Kanki et al. ${ }^{47}$, 
com prostitutas de Dakar, no Senegal. Apesar do número de mulheres infectadas por cada subtipo (A, C, D e G) ter sido pequeno, os autores encontraram uma associação significativa entre subtipo A e tempo de sobrevida sem AIDS.

A seguir, Kaleebu et al. 48,49 mostraram que infecções pelo subtipo A estavam associadas a taxas de progressão mais lentas para a AIDS do que infecções pelo subtipo D. Apesar das potenciais fontes de vício desses estudos, como o fato de não terem sido desenhados com o objetivo específico de se estudar possíveis diferenças na progressão da imunodeficiência entre subtipos, o grande tamanho da amostra estudada e o fato de os trabalhos terem sido desenvolvidos em uma região onde a terapia anti-retroviral freqüentemente não está disponível favorecem a consistência dos seus resultados 48,49 .

Além da possibilidade de subtipos diferirem quanto à progressão para a AIDS, o tempo de sobrevida sem AIDS, no Brasil, é superior para os pacientes infectados pelo sorotipo $\mathrm{BBr}$ em relação àqueles infectados pelo sorotipo B 50,51.

\section{Outras evidências}

Os indícios de que variantes de HIV-1 podem estar associadas a taxas diferentes de progressão para a AIDS não se restringem aos resultados das análises de sobrevida conduzidas nos últimos anos. Um fato que tem recebido atenção é a recente expansão do subtipo C na epidemia mundial 6 . Neste sentido, foi mostrado que vírus do subtipo $C$ não utilizam o co-receptor CXCR4 e nem adquirem a capacidade de induzir sincício em células MT-02 nas fases tardias da imunodeficiência, como é normalmente observado para os vírus dos demais subtipos 52 . Além disto, as mutações para aminoácidos básicos nas posições 306 e 320 da alça V3 freqüentemente associadas à aquisição da capacidade de formar sincícios estão ausentes nos vírus do subtipo C 12,52,53.

Recentemente, foi mostrado que vírus do subtipo C replicam com menos eficiência em células mononucleares e em linfócitos T CD4+ in vitro do que isolados do subtipo B; por outro lado, a eficiência de replicação em células de Langerhans, abundantes no trato genital e importantes na infecção primária por contato sexual, foi igual para os dois subtipos 54 . Segundo os autores, a menor eficiência de replicação do subtipo C em macrófagos e linfócitos T poderia resultar em uma progressão mais lenta da imunodeficiência nos pacientes infectados e, conseqüentemente, em uma maior aptidão para se disseminar na epidemia.
Contudo, se essa menor eficiência na replicação em células T CD4+ e em células mononucleares também ocorre nos pacientes infectados (in vivo), poder-se-ia esperar que a infecção pelo subtipo C cursasse com níveis de cargas virais inferiores. Em um estudo seccional, entretanto, foi mostrado que mulheres infectadas por vírus $C$ possuíam níveis de carga viral mais elevados do que aquelas com vírus dos subtipos A, D ou G 55. Contudo, a natureza do estudo não permitiu que se discriminasse entre as possibilidades das pacientes com vírus $\mathrm{C}$ estarem infectadas a mais tempo ou terem um tempo de progressão menor para AIDS.

\section{Monitoramento das epidemias regionais}

A permanente circulação geográfica dos grupos, subtipos e CRFs do HIV-1 permite que estas variantes sejam empregadas como marcadores da epidemia e que a caracterização dos vírus circulantes em cada país seja útil aos programas de vigilância epidemiológica locais, como ocorre na Tailândia 56 e nos Estados Unidos 57. Por exemplo, a caracterização da variabilidade viral em regiões ou grupos de indivíduos onde originalmente somente um subtipo era encontrado, permite que se monitore as reintroduções do HIV-1 nas populações. Nestes casos, de um modo geral, os grupos selecionados são principalmente imigrantes 27,58,59,60, indivíduos sob alto risco para a infecção pelo HIV-1 61,62 e militares que prestam serviço no exterior 57,63. Além disto, em países como a Tailândia, onde se observa a segregação parcial de variantes segundo a via de infecção, o acompanhamento da diversidade do HIV-1 dentro dos grupos sob riscos distintos pode informar sobre o fluxo de vírus entre eles 64 .

Nos Estados Unidos, um sítio sentinela para o monitoramento da infecção pelo HIV é a região sul do Bronx, em Nova York. Diversos fatores contribuem para esta escolha: a região possui uma das maiores prevalências de HIV do país, uma das maiores proporções de indivíduos sob risco para a infecção e um grande número de imigrantes e turistas do Caribe, América Latina e África 58,60,65. De fato, um estudo conduzido na região foi um dos primeiros a mostrar infecções por subtipos não-B do grupo M (no caso, subtipos A e F) no país e o primeiro a identificar a presença de vírus recombinates B/F na América do Norte 60 . Ainda nos Estados Unidos, outro estudo sentinela envolvendo todo o sistema de vigilância nacional mostrou a introdução de vírus do grupo O no país 59 . 
A introdução de novas variantes a partir da imigração também foi observada em diversos países da Europa. Na primeira década da epidemia, o subtipo B era virtualmente a única variante encontrada na região. Entretanto, ao longo dos anos 90, outros subtipos foram progressivamente identificados em países como França 66, Suécia 67 e Holanda 68. Apesar dos padrões de distribuição dos subtipos não-B diferirem entre os países europeus, na maioria dos casos esses subtipos foram inicialmente identificados em imigrantes africanos, asiáticos ou latino-americanos e, posteriormente, em nativos dos próprios países.

A importância da vigilância epidemiológica para a entrada de novas variantes nos países afetados pela pandemia ficou evidente quando os vírus dos grupos $\mathrm{O}$ e $\mathrm{N}$ foram identificados. $\mathrm{Na}$ época, foi demonstrado que nem todos os ensaios imunoenzimáticos então utilizados para o diagnóstico sorológico da infecção pelo HIV-1 eram capazes de detectar infecções por cepas particularmente divergentes, como os vírus dos grupos $\mathrm{O}$ e $\mathrm{N} 5,21$.

\section{Reconstrução da história de epidemias}

Um exemplo da aplicação da classificação do HIV-1 em subtipos na reconstrução histórica de epidemias regionais é o caso da Tailândia. Nesse país, poucos casos de infecção haviam sido detectados até a metade da década de 80 quando, nos últimos anos da década, registrou-se um aumento dramático na incidência de casos entre usuários de drogas injetáveis 69 e, a seguir, entre jovens do sexo masculino, infectados por contato heterossexual 70. A caracterização molecular de amostras de HIV-1 dos dois grupos mostrou que ambos portavam vírus diferentes: entre os usuários de drogas predominava uma variante distinta do subtipo B (variante B') 69,71, enquanto a maioria dos indivíduos infectados por contato sexual possuía vírus até então desconhecidos, classificados inicialmente como subtipo E 71. Posteriormente, foi demonstrado que os vírus do subtipo E, na verdade, representam uma forma recombinante, formada pelos subtipos A e E (CRF01_AE) 72.

A segregação parcial de variantes segundo grupo de risco na Tailândia foi observada por outros autores nos anos seguintes 73,74. Atualmente, a maioria dos casos incidentes de infecção pelo HIV-1 na Tailândia é atribuída aos vírus CRF01_AE 75, sendo possível que, no futuro, este se torne o subtipo majoritário no país. De qualquer forma, independentemente do curso atual e futuro da epidemia tailandesa, a segregação parcial das variantes B' e CRF01_AE observada durante a primeira década da epidemia mostra que a introdução do HIV-1 nesse país ocorreu em pelo menos duas ocasiões.

Outro exemplo disponível é a explosão de casos de infecção entre usuários de drogas injetáveis que ocorreu na Europa Oriental na segunda metade da década de 90 . Em um primeiro momento, foi observado um grande número de casos associados a vírus do subtipo A extremamente similares entre si, bem como algumas infecções por cepas muito semelhantes do subtipo B 76,77. A grande similaridade encontrada dentro das populações de vírus de cada subtipo sugere que cada um tenha sido introduzido dentro do grupo de usuários de drogas uma única vez 76,77 .

Em seguida, na mesma população, registrou-se uma explosão de casos de infecção por vírus recombinantes $\mathrm{AB}$ (CRF03_AB), também extremamente homogêneos 61 . A análise molecular destes vírus sugeriu que os seus segmentos A e B parentais haviam sido fornecidos por vírus dos dois subtipos que circulavam na mesma população, mais especificamente na Ucrânia. Com base nestes resultados, foi possível inferir que os eventos de recombinação que deram origem ao recombinante $\mathrm{AB}$ ocorreram dentro da própria população de usuários de drogas, no curso da epidemia 78 .

Em alguns países do norte da Europa foi observada uma segregação na transmissão de variantes do subtipo B entre usuários de drogas injetáveis e homossexuais. Neste caso, os vírus encontrados nos dois grupos possuem padrões de mutação específicos nas seqüências de nucleotídeos e de aminoácidos de determinados segmentos do seu genoma (revisado por Kuiken et al. 79 ).

\section{Outras abordagens}

A análise filogenética das seqüências das variantes do vírus permite a abordagem de outras questões referentes à epidemia como, por exemplo, o momento em que determinadas variantes foram introduzidas em uma população susceptível. Para a epidemiologia, a determinação de escalas temporais pode ser útil não somente para fins descritivos, como também para se testar diferentes hipóteses acerca da evolução dos patógenos ${ }^{80}$. No caso do HIV-1, os modelos construídos para se estimar o tempo de divergência entre espécies podem ser aplicados para a reconstrução da origem da pandemia na espécie humana 81 , para se estimar o momento da introdução de variantes em populações es- 
pecíficas 82,83 , bem como para se estudar a história evolutiva de variantes do vírus 84 .

Uma abordagem nova e promissora é a utilização das informações contidas nos genomas dos patógenos para se inferir a dinâmica da evolução da interação hospedeiro-parasita. Esta abordagem foi denominada filodinâmica 85 . Nos modelos desenvolvidos para as inferências filodinâmicas, os autores buscam integrar aspectos relevantes para a diversidade dos parasitas, como suas taxas de mutação e adaptação, a resposta imune dos hospedeiros e a dinâmica das epidemias, para a compreensão dos diversos padrões observados nas filogenias de patógenos 85

Os modelos de filodinâmica propõem o estudo da evolução da diversidade dos patógenos em diferentes escalas, desde as populações encontradas em um único hospedeiro até a diversidade entre os indivíduos que compõem a epidemia. Nestes modelos, os vírus RNA, como o HIV, têm merecido destaque por apresentarem altas taxas de mutação, grandes populações virais e pequenos tempos de geração, o que sugere que os processos epidemiológicos e genético-populacionais ocorrem em escalas de tempo similares 85 .

\section{Resumo}

Uma das características mais marcantes do HIV-1 é a imensa diversidade observada entre as cepas que compõem a pandemia de HIVIAIDS. Na última década, a classificação das variantes do vírus em grupos, subtipos e formas recombinantes circulantes (CRF) e a observação de padrões específicos de mutação têm provado serem ferramentas poderosas para os estudos da dinâmica molecular do vírus. O acompanhamento da distribuição mundial da diversidade do HIV-1 tem sido empregado, por exemplo, em programas de vigilância epidemiológica, bem como na reconstrução da história de epidemias regionais. Além disto, a observação de padrões específicos de distribuição espacial do vírus sugere a existência de diferenças na patogenia e transmissibilidade entre os diversos subtipos. A análise molecular das seqüências do vírus também permite a estimativa do tempo de divergência entre as variantes e das forças dinâmicas que modelam as árvores filogenéticas.

HIV-1; Síndrome de Imunodeficiência Adquirida; Epidemiologia Molecular

\section{Conclusões}

A distribuição geográfica das variantes do HIV-1 (grupos, subtipos e CRFs) é heterogênea, diferindo em extensão e temporalmente. A dinâmica populacional das variantes é favorecida pela intensa circulação de indivíduos infectados, apesar de existirem indícios de que o fenótipo dos vírus, expresso na sua transmissibilidade e patogenia, possa contribuir para o estabelecimento de epidemias, favorecendo alguns subtipos em detrimento de outros, como no caso do subtipo C. Além disto, a caracterização das cepas prevalentes nos países afetados pela pandemia permite que se acompanhe a trajetória mundial do vírus, seja retrospectivamente, reconstruindo-se a introdução de variantes nas diferentes populações, seja monitorando-se as reintroduções do HIV-1 em grupos com alto risco para a infecção. Desta forma, o monitoramento da diversidade molecular das variantes do vírus, obtidas das diferentes populações infectadas e em diferentes momentos, tem se mostrado uma ferramenta útil para o estudo da pandemia de AIDS. Recentemente, a filodinâmica surge como uma perspectiva promissora, integrando aspectos da evolução dos parasitas, da resposta imune dos hospedeiros e dos fatores ecológicos envolvidos na origem e na progressão das epidemias.

\section{Colaboradores}

M. E. Pinto foi responsável por sua concepção, coleta e análise de dados. C. J. Struchiner participou na concepção e interpretação dos resultados.

\section{Agradecimentos}

Agradecemos à Fundação Carlos Chagas Filho de Amparo à Pesquisa do Estado do Rio de Janeiro e ao Conselho Nacional de Desenvolvimento Científico e Tecnológico, pelo financiamento do suporte computacional recebido pelos doutores Claudio José Struchiner e Cláudia Augusta de Moraes Russo, necessário ao desenvolvimento deste trabalho, e ao Doutor Antônio Mateu Solé-Cava pela revisão do texto. 


\section{Referências}

1. McDade JE, Anderson BE. Molecular epidemiology: applications of nucleic acid amplification and sequence analysis. Epidemiol Rev 1996; 18:90-7.

2. Loussert-Ajaka I, Chaix ML, Korber B, Letourneur F, Gomas E, Allen E, et al. Variability of human immunodeficiency virus type 1 group $\mathrm{O}$ strains isolated from Cameroonian patients living in France. J Virol 1995; 69:5640-9.

3. Rambaut A, Posada D, Crandall KA, Holmes EC. The causes and consequences of HIV evolution. Nat Rev Genet 2004; 5:52-61.

4. Gürtler L, Hauser PH, Eberle J, von Brunn A, Knapp S, Zekeng L, et al. A new subtype of human immunodeficiency virus type 1 (MVP-5180) from Cameroon. J Virol 1994; 68:1581-5.

5. Simon F, Mauclère P, Roques P, Loussert-Ajaka I, Müller-Trutwin MC, Saragosti S, et al. Identification of a new human immunodeficiency virus type 1 distinct from group $\mathrm{M}$ and group $\mathrm{O}$. Nat Med 1998; 4:1032-7.

6. Osmanov S, Pattou C, Walter N, Schwartänder B, Esparza J; WHO-UNAIDS Network for HIV Isolation and Characterization. Estimated global distribution and regional spread of HIV-1 genetic subtypes in the year 2000. J Acquir Immune Defic Syndr 2002; 29:184-90.

7. Overbaugh J, Bangham CRM. Selection forces and constrains on retroviral sequence variation. Science 2001; 292:1106-9.

8. Markowitz M, Louie M, Hurley A, Sun E, Mascio MD, Perelson AS, et al. A novel antiviral intervention results in more accurate assessment of human immunodeficiency virus type 1 replication dynamics and T-cell decay in vivo. J Virol 2003; 77:5037-8.

9. Hu WS, Temin HM. Retroviral recombination and reverse transcription. Science 1990; 250:1227-33.

10. Janini LM, Tanuri A, Schechter M, Peralta JM, Vicente ACP, Torre ND, et al. Horizontal and vertical transmission of human immunodeficiency virus type 1 dual infections caused by viruses of subtypes B and C. J Infect Dis 1998; 177:227-31.

11. Quiñones-Mateu ME, Arts EJ. Fitness: implications for drug resistence, disease progression, and global epidemic evolution. In: Kuiken CL, Foley B, Hahn B, Korber B, Marx PA, McCutchan F, et al. editors. HIV sequence compendium. Los Alamos: Theoretical Biology and Biophysics Group, Los Alamos National Laboratory; 2001. p. 134-70.

12. Fouchier RAM, Groenink M, Kootstra NA, Tersmette M, Huisman HG, Miedema F, et al. Phenotype-associated sequence variation in the third variable domain of the human immunodeficiency virus type 1 gp120 molecule. J Virol 1992; 66: 3183-7.

13. Hahn BH, Shaw GM, De Cock KM, Sharp PM. AIDS as a zoonosis: scientific and public health implications. Science 2000; 287:607-14.

14. Hirsch VM, Olmsted RA, Murphey-Corb M, Purcell RH, Johnson PR. An African primate lentivirus $\left(\mathrm{SIV}_{\mathrm{sm}}\right)$ closely related to HIV-2. Nature 1989; 339: 389-92.

15. Fukasawa M, Miura T, Hasegawa A, Morikawa S, Tsujimoto H, Miki K, et al. Sequence of simian immunodeficiency virus from african green monkey, a new member of the HIV/SIV group. Nature 1988; 333:457-61.

16. Doolittle RF, Feng DF, Mcclure MA, Johnson MS. Retrovirus phylogeny and evolution. Curr Top Microbiol Immunol 1990; 157:1-18.

17. Vidal N, Peeters M, Mulanga-Kabeya C, Nzilambi $\mathrm{N}$, Robertson D, Ilunga W, et al. Unprecedented degree of human immunodeficiency virus yype 1 (HIV-1) group M genetic diversity in the Democratic Republic of Congo suggests that the HIV-1 pandemic originated in Central Africa. J Virol 2000; 74:10498-507.

18. Zhu T, Korber B, Nahmias AJ, Hooper E, Sharp PM, Ho DD. An African HIV-1 sequence from 1959 and implications for the origin of the epidemic. Nature 1998; 391:594-7.

19. Huet T, Cheynier R, Meyerhans A, Roelants G, Wain-Hobson S. Genetic organization of a chimpanzee lentivirus related to HIV-1. Nature 1990; 345:356-9.

20. Hayami M, Ido E, Miura T. Survey of simian immunodeficiency virus among nonhuman primate populations. Curr Top Microbiol Immunol 1994; 188:1-19.

21. HIV-1 subtypes: implications for epidemiology, pathogenicity, vaccines and diagnostics. Workshop Report from the European Commission (DG XII, INCO-DC) and the Joint United Nations Programme on HIV/AIDS. AIDS 1997; 11:17-36.

22. Delwart EL, Shpaer EG, Louwagie J, McCutchan FE, Grez M, Rübsamen-Waigmann $\mathrm{H}$, et al. Genetic relationships determined by a DNA heteroduplex mobility assay: analysis of HIV-1 env genes. Science 1993; 262:1257-61.

23. Bachmann MH, Delwart EL, Shpaer EG, Lingenfelter P, Singal R, Mullins JI, et al. Rapid genetic characterization of HIV type 1 strains from four World Health Organization-sponsored vaccine evaluation sites using a heteroduplex mobility assay. AIDS Res Hum Retroviruses 1994; 10:1345-53.

24. Heyndrickx L, Janssens W, Zekeng L, Musonda R, Anagonou S, van der Awera G, et al. Simplified strategy for detection of recombinant human immunodeficiency virus type 1 group $M$ isolates by gag/env heteroduplex mobility assay. J Virol 2000; 74:363-70.

25. Pieniazek D, Janini LM, Ramos A, Tanuri A, Schechter M, Peralta JM, et al. HIV-1 patients may harbor viruses of different phylogenetic subtypes: implications for the evolution of the HIV/AIDS pandemic. Emerg Infect Dis 1995; 1:86-8.

26. Pinto ME, Tanuri A, Schechter M. Molecular and epidemiologic evidence for the discontinuous introduction of subtypes B and F into Rio de Janeiro, Brazil. J Acquir Immune Defic Syndr Hum Retrovirol 1998; 19:310-2.

27. Holguín A, Rodés B, Dietrich U, Soriano V. Human Immunodeficiency Virus Type 1 subtypes circulating in Spain. J Med Virol 1999; 59:189-93.

28. Morgado MG, Guimarães ML, Neves JRI, Santos VGV, Carvalho MIL, Castello-Branco LR, et al. Molecular epidemiology of HIV in Brazil: polymorphism of the antigenically distinct HIV-1 B 
subtype strains. Mem Inst Oswaldo Cruz 1998; 93:383-6.

29. Covas DT, Bíscaro TA, Kashima S, Duarte G, Machado AA. High frequency of the GWG (Pro Trp) envelope variant of HIV-1 in Southeast Brazil. J Acquir Immune Defic Syndr Hum Retrovirol 1998; 19:74-9.

30. Guimarães ML, dos Santos Moreira A, Loureiro R, Galvão-Castro B, Morgado MG; Brazilian Network for HIV Isolation and Characterization. High frequency of recombinant genomes in HIV type 1 samples from Brazilian southeastern and southern regions. AIDS Res Hum Retroviruses 2002; 18:1261-9.

31. Peeters M. Recombinant HIV sequences: their role in the global epidemics. In: Kuiken CL, Foley B, Hahn B, Korber B, Marx PA, McCutchan F, et al. editors. HIV sequence compendium. Los Alamos: Theoretical Biology and Biophysics Group, Los Alamos National Laboratory; 2000. p. 2-23.

32. Lukashov VV, Huismans R, Rakhmanova AG, Lisitsina ZN, Akhtyrskaya NA, Vlasov NN, et al. Circulation of subtype $\mathrm{A}$ and gagA/envB recombinant HIV type 1 strains among injecting drug users in St. Petersburg, Russia, correlates with geographical origin of infections. AIDS Res Hum Retroviruses 1999; 15:1577-83.

33. Fonjungo PN, Mpoudi EN, Torimiro JN, Alemnji GA, Eno LT, Nkengasong JN, et al. Presence of diverse human immunodeficiency virus type 1 viral variants in Cameroon. AIDS Res Hum Retroviruses 2000; 16:1319-24.

34. Thomson MM, Delgado E, Manjon N, Ocampo A, Villahermosa ML, Marino A, et al. HIV-1 genetic diversity in Galicia Spain: BG intersubtype recombinant viruses circulating among injecting drug users. AIDS 2001; 15:509-16.

35. Yirrell DY, Kaleebu P, Morgan D, Watera C, Magambo B, Lyagoba F, et al. Inter and intra-genetic intersubtype HIV-1 recombination in rural and semi-urban Uganda. AIDS 2002; 16:279-86.

36. Soto-Ramirez LE, Renjifo B, Mclane MF, Marlink R, O'Hara C, Sutthent R, et al. HIV-1 Langerhans' cell tropism associated with heterosesual transmission of HIV. Science 1996; 271:1291-3.

37. Emiliani S, Blanc M, Devaux C. p17 gag sequence of HIV- $1_{\mathrm{GER}}$, a new, highly replicative and highly cytopathic HIV type 1 strain of D genotype. AIDS Res Hum Retroviruses 1994; 10:1043-5.

38. Vlahov D, Graham N, Hoover D, Flynn C, Bartlett JG, Margolick JB, et al. Prognostic indicators for AIDS and infectious disease death in HIV-infected injection drug users: plasma viral load and CD4+ cell count. JAMA 1998; 279:35-40.

39. Alaeus A. Significance of HIV-1 genetic subtypes. Scand J Infect Dis 2000; 32:455-63.

40. Sterling TR, Vlahov D, Astemborski J, Hoover DR, Margolick JB, Quinn TC. Initial plasma HIV-1 RNA levels and progression to AIDS in women and men. N Engl J Med 2001; 344:720-5.

41. Essex E. Human immunodeficiency viruses in the developing world. Adv Virus Res 1999; 53:71-88.

42. van Harmelen J, Wood R, Lambrick M, Rybicki EB, Williamson AL, Williamson C. An association between HIV-1 subtypes and mode of transmission in Cape Town, South Africa. AIDS 1997; 11:81-7.
43. Dittmar MT, Simmons G, Hibbitts S, O'Hare M, Louisirirotchanakul S, Beddows S, et al. Langerhans cell tropism of human immunodeficiency virus type 1 subtype A through $\mathrm{F}$ isolates derived from different transmission groups. J Virol 1997; 71:8008-13.

44. Pope M, Ho DD, Moore JP, Weber J, Dittmar MT. Different subtypes of HIV-1 and cutaneous dendritic cells. Science 1997; 278:786-8.

45. Karita E, Nkengasong JN, Willems B, Vanham G, Fransen K, Heyndrickx L, et al. Macrophage-tropism of HIV-1 isolates of different genetic subtypes. AIDS 1997; 11:1303-4.

46. Korber BTM, MacInnes K, Smith RF, Myers G. Mutational trends in the V3 loop protein sequences observed in different genetic lineages of human immunodeficiency virus type 1. J Virol 1994; 68: 6730-44.

47. Kanki PJ, Hamel DJ, Sankalé JL, Hsieh CC, Thior I, Barin F, et al. Human immunodeficiency virus type 1 subtypes differ in disease progression. J Infect Dis 1999; 179:68-73.

48. Kaleebu P, Ross A, Morgan D, Yirrell D, Oram J, Rutemberwa A, et al. Relationship between HIV-1 env subtypes $\mathrm{A}$ and $\mathrm{D}$ and disease progression in a rural ugandan cohort. AIDS 2001; 15:293-9.

49. Kaleebu P, French N, Mahe C, Yirrell D, Watera C, Lyagoba F, et al. Effect of human immunodeficiency virus (HIV) type 1 envelope subtypes A and $\mathrm{D}$ on disease progression in a large cohort of HIV-1-positive persons in Uganda. J Infect Dis 2002; 185:1244-50.

50. Santoro-Lopes G, Harrison LH, Tavares MD, Xexéo A, Dos Santos ACE, Schechter M. HIV disease progression and V3 serotypes in Brazil: is B different from B-Br? AIDS Res Hum Retroviruses 2000; 16:953-8.

51. Casseb J, Komninakis S, Abdalla L, Brigido LF, Rodrigues R, Araujo F, et al. HIV disease progression: is the Brazilian variant subtype B' (GWGR motif) less pathogenic than US/European subtype $B$ (GPGR)? Int J Infect Dis 2002; 6:164-9.

52. Treurnicht FK, Smith TL, Engelbrecht S, Claassen M, Robson BA, Zeier M, et al. Genotypic and phenotypic analysis of the $e n v$ gene from South African HIV-1 subtype B and C isolates. J Med Virol 2002; 68:141-6.

53. Fouchier RAM, Schuitemaker H. Molecular determinants of human immunodeficiency virus type 1 phenotype variability. Eur J Clin Invest 1996; 26:175-85.

54. Ball SC, Abraha A, Collins KR, Marozsan AJ, Baird $\mathrm{H}$, Quiñones-Mateu ME, et al. Comparing the ex vivo fitness of CCR5-tropic human immunodeficiency virus type 1 isolates of subtypes B and C. J Virol 2003; 77:1021-38.

55. Neilson JR, John GC, Carr JK, Lewis P, Kreiss JK, Jackson S, et al. Subtypes of human immunodeficiency virus type 1 and disease stage among women in Nairobi, Kenya. J Virol 1999; 73:4393403.

56. Mason CJ, Kitsiripornchai S, Markowitz LE, Chanbancherd P, Supapongse T, Jugsudee A, et al. Nationwide surveillance of HIV-1 prevalence and subtype in young Thai men. J Acquir Immune Defic Syndr Hum Retrovirol 1998; 19:165-73. 
57. Brodine SK, Shaffer RA, Starkey MJ, Tasker SA, Gilcrest JL, Louder MK, et al. Drug resistance patterns, genetic subtypes, clinical features, and risk factors in military personnel with HIV-1 seroconversion. Ann Intern Med 1999; 131:502-6.

58. Irwin KL, Pau CP, Lupo D, Pienazek D, Luo CC, Olivo N, et al. Presence of human immunodeficiency virus (HIV) type 1 subtype A infection in a New York community with high HIV prevalence: a sentinel site for monitoring HIV genetic diversity in North America. J Infect Dis 1997; 176:1629-33.

59. Sullivan PS, Do AN, Ellenberger D, Pau CP, Paul S, Robbins K, et al. Human immunodeficiency virus (HIV) subtype surveillance of African-born persons at risk for group $\mathrm{O}$ and group N HIV infections in the United States. J Infect Dis 2000; 181:463-9.

60. Weidle PJ, Ganea CE, Irwin KL, Pienazek D, Mcgowan JP, Olivo N, et al. Presence of human immunodeficiency virus (HIV) type 1 , group $\mathrm{M}$, non-B subtypes, Bronx, New York: a sentinel site for monitoring HIV genetic diversity in the United States. J Infect Dis 2000; 181:470-5.

61. Bobkov A, Kazennova E, Selimova L, Bobkova M, Khanina T, Ladnaya N, et al. A sudden epidemic of HIV type 1 among injecting drug users in the former Soviet Union: identification of subtype A, subtype B, and novel gagA/envB recombinants. AIDS Res Hum Retroviruses 1998; 14:669-76.

62. Hussein M, Abebe A, Pollakis G, Brouwer M, Petros B, Fontanet AL, et al. HIV-1 subtype C in commerical sex workers in Addis Ababa, Ethiopia. J Acquir Immune Defic Syndr 2000; 23:120-7.

63. Lasky M, Perret JL, Peeters M, Bibollet-Ruche F, Liegeois F, Patrel D, et al. Presence of multiple non-B subtypes and divergent subtype B strains of HIV-1 in individuals infected after overseas deployment. AIDS 1997; 11:43-51.

64. Limpakarnjanarat K, Ungchusak K, Mastro TD, Young NL, Likhityingvara C, Sangwonloy O, et al. The epidemiological evolution of HIV-1 subtypes $\mathrm{B}$ and $\mathrm{E}$ among heterosexuals and injecting drug users in Thailand, 1992-1997. AIDS 1998; 12:11089.

65. Irwin KL, Olivo N, Schable C, Weber JT, Janssen R, Ernst J. Absence of human immunodeficiency virus type 2 infection among patients in a hospital serving a New York community at high risk for infection. Transfusion 1996; 36:731-3.

66. Barin F, Courouce AM, Pillonel J, Buzelay L. Increasing diversity of HIV-1 M serotypes in French blood donors over a 10-year period (1985-1995). AIDS 1997; 11:1503-8.

67. Alaeus A, Leiner T, Lidman K, Albert J. Most HIV-1 genetic subtypes have entered Sweden. AIDS 1997; 11:199-202.

68. Op de Coul ELM, Coutinho RA, van der Schoot A, van Doornum GJJ, Lukashov VV, Goudsmit J, et al. The impact of immigration on the env HIV-1 subtype distribution among heterosexuals in the Netherlands: influx of subtype B and non-B strains. AIDS 2001; 15:2277-86.

69. McCutchan FE, Hegerich PA, Brennan TP, Phanuphak P, Singharaj P, Jugsudee A, et al. Genetic variants of HIV-1 in Thailand. AIDS Res Hum Retroviruses 1992; 8:1887-95.
70. Nopkesorn T, Mastro TD, Sangkharomya S, Sweat M, Singharaj P, Limpakarnjanarat K, et al. HIV-1 infection in young men in northern Thailand. AIDS 1993; 7:1233-9.

71. Kalish ML, Baldwin A, Raktham S, Wasi C, Luo CC, Schochetman G, et al. The evolving molecular epidemiology of HIV-1 envelope subtypes in injecting drug users in Bangkok, Thailand: implications for HIV vaccine trials. AIDS 1995; 9:851-7.

72. Gao F, Robertson DL, Morrison SG, Hui H, Craig $\mathrm{S}$, Decker J, et al. The heterosexual human immunodeficiency virus type 1 epidemic in Thailand is caused by an intersubtype (A/E) recombinant of African origin. J Virol 1996; 70:7013-29.

73. Subbarao S, Limpakarnjanarat K, Mastro TD, Bhumisawasdi J, Warachit P, Jayavasu C, et al. HIV type 1 in Thailand, 1994-1995: persistence of two subtypes with low genetic diversity. AIDS Res Hum Retroviruses 1998; 14:319-27.

74. Kitayaporn D, Vanichseni S, Mastro TD, Raktham S, Vaniyapongs T, Des Jarlais DC, et al. Infection with HIV-1 subtypes B and E in injecting drug users screened for enrollment into a prospective cohort in Bangkok, Thailand. J Acquir Immune Defic Syndr Hum Retrovirol 1998; 19:289-95.

75. Subbarao S, Vanichseni S, Hu DJ, Kitayaporn D, Choopanya K, Raktham S, et al. Genetic characterization of incident HIV type 1 subtype E and B strains from a prospective cohort of injecting drug users in Bangkok, Thailand. AIDS Res Hum Retroviruses 2000; 16:699-707.

76. Bobkov A, Cheingsong-Popov R, Selimova L, Ladnaya N, Kazennova E, Kravchenko A, et al. An HIV type 1 epidemic among injecting drug users in the former Soviet Union caused by a homogeneous subtype A strain. AIDS Res Hum Retroviruses 1997; 13:1195-201.

77. Lukashov VV, Karamov EV, Eremin VF, Titov LP, Goudsmit J. Extreme founder effect in an HIV type 1 subtype A epidemic among drug users in Svetlogorsk, Belarus. AIDS Res Hum Retroviruses 1998; 14:1299-303.

78. Liitsola K, Holm K, Bobkov A, Pokrovsky V, Smolskaja T, Leinikki P, et al. An AB recombinant and its parental HIV type 1 strains in the area of the former Soviet Union: low requirements for sequence identity in recombination. AIDS Res Hum Retroviruses 2000; 16:1047-53.

79. Kuiken C, Thakallapalli R, Eskild A, De Ronde A. Genetic analysis reveals epidemiologic patterns in the spread of human immunodeficiency virus. Am J Epidemiol 2000; 152:814-22.

80. Lemey P, Salemi M, Wang B, Duffy M, Hall WH, Saksena NK, et al. Site stripping based on likelihood ratio reduction is a useful tool to evaluate the impact of non-clock-like behavior on viral phylogenetic reconstructions. FEMS Immunol Med Microbiol 2003; 39:125-32.

81. Korber B, Muldoon M, Theiler J, Gao F, Gupta R, Lapedes A, et al. Timing the ancestor of the HIV-1 pandemic strains. Science 2000; 288:1789-96.

82. Abebe A, Lukashov VV, Pollakis G, Kliphuis A, Fontanet AL, Goudsmit J, et al. Timing of the HIV1 subtype $C$ epidemic in Ethiopia based on early virus strains and subsequent virus diversification. AIDS 2001; 15:1555-61. 
83. Robbins KE, Lemey P, Pybus OG, Jaffe HW, Youngpairoj AS, Brown TM, et al. U.S. human immunodeficiency virus type 1 epidemic: date of origin, population history, and characterization of early strains. J Virol 2003; 77:6359-66.

84. Lukashov VV, Goudsmit J. Recent evolutionary history of human immunodeficiency virus type 1 subtype B: reconstruction of epidemic onset based on sequence distances to the common ancestor. J Mol Evol 2002; 54:680-91.

85. Grenfell BT, Pybus OG, Gog JR, Wood JLN, Daly JM, Mumford JA, et al. Unifying the epidemiological and evolutionary dynamics of pathogens. Science 2004; 303:327-32.

Recebido em 04/Ago/2004

Versão final reapresentada em 28/Jun/2005

Aprovado em 05/Ago/2005 